\title{
A Preliminary Study in the Effect of Astragali radix, a Qi-Invigorating Herb, on Mitochondria: Insights at Cellular Level and Mouse Tissues Level
}

\author{
Yu Chen ${ }^{*}$, Mengmei Li ${ }^{*}$, Zhongzhen Cai ${ }^{1}$, Yuming Chen' ${ }^{1}$, Lin Wang1, Jie Teng1, Qian Feng1, \\ Caixia Li' ${ }^{1}$, Glen Rein ${ }^{2}$, Bruce Qing Tang1, Xuemei Bai ${ }^{1 \#}$
}

${ }^{1}$ ENNOVA Institute of Life Science and Technology, ENN Group, Langfang, China

${ }^{2}$ Quantum Biology Research Laboratory, Ridgway, USA

Email: "baixuemei@enn.cn

How to cite this paper: Chen, Y., Li, M.M., Cai, Z.Z., Chen, Y.M., Wang, L., Teng, J., Feng, Q., Li, C.X., Rein, G., Tang, B.Q. and Bai, X.M. (2020) A Preliminary Study in the Effect of Astragali radix, a Qi-Invigorating Herb, on Mitochondria: Insights at Cellular Level and Mouse Tissues Level. Chinese Medicine, 11, 113-125.

https://doi.org/10.4236/cm.2020.113007

Received: August 22, 2020

Accepted: September 27, 2020

Published: September 30, 2020

Copyright $\odot 2020$ by author(s) and Scientific Research Publishing Inc. This work is licensed under the Creative Commons Attribution International License (CC BY 4.0).

http://creativecommons.org/licenses/by/4.0/

\section{(c) (i) Open Access}

\begin{abstract}
Objectives: To explore the effects of Qi-invigorating herbs on mitochondrial function using cultured cells and animal organs. Methods. Using water extracts of Astragali radix, we investigated the effect of "Qi-invigoration" on M-1 renal cells and mouse organs in-vitro including total adenylate production (TAP), reactive oxygen species (ROS) levels, and mitochondrial membrane potential (MMP). We also examined the effect on antioxidant capacity by conducting an analysis of superoxide dismutase (SOD) and glutathione (GSH). Results. 1) Astragali radix increased mitochondrial TAP generation and decreased ROS levels in both mouse kidney tissues and M-1 renal cells. 2) Astragali radix also significantly increased MMP and GSH levels in M-1 cells, but in the kidney tissue, there was no significant change in MMP levels and a decrease in GSH levels. 3) Astragali radix stimulated TAP levels in the heart, spleen, lung, kidney and skeletal muscle tissue, which was accompanied by the reduction of ROS. 4) For the meridian organs that Astragali radix belongs to, the energy production and antioxidant capacity were boosted simultaneously. Conclusions. These results provide new insights for the biochemical basis of Qi-invigoration and the meridian tropism theory for this Qi-invigorating herb.
\end{abstract}

\section{Keywords}

Qi, Astragali radix, Mitochondria, Total Adenylate, Antioxidant Capacity

*The authors Yu Chen and Mengmei Li contributed equally to the work. 


\section{Introduction}

In Traditional Chinese Medicine (TCM), herbs are generally classified into four categories according to their functions which include Yang-invigorating, Yin-nourishing, Qi-invigorating and blood-enriching herbs. Astragali radix, known as "Huang Qi", belongs to the class of Qi-invigorating herbs and is used for the treatment of Qi deficiency diseases. Up to now, studies have shown that Astragali radix has a variety of biological functions, and plays significant regulatory roles in cell antioxidant activity, apoptosis, immunity and other aspects [1]-[6]. In view of its important role, Astragali radix has been used in the treatment of many diseases for hundreds of years [7] [8] [9].

Mitochondrion is an organelle which exists in nearly all eukaryotic cells with the main role of providing adenosine triphosphate (ATP) for cellular functions through oxidative phosphorylation. When ATP is generated in mitochondria, a small amount of electrons will leak out of the electron transport chain, forming reactive oxygen species (ROS) [8] [9] [10]. The overproduction of ROS can cause an oxidative stress reaction in mitochondria and in serious cases, lead to mitochondrial dysfunction. This affects the normal life activities of cells causing a variety of diseases and accelerating the aging process [11] [12] [13].

Considering the outstanding antioxidant capacity of Astragali radix, more and more attention has been paid to research on Astragali radix and mitochondria. Some studies have shown that Astragali radix can reduce the dysfunction of mesenchymal stem cells by inhibiting ROS in mitochondrion [14]. Studies with mouse myoblasts showed that Astragali radix exacts and Astragali radix polysaccharides (ARS) could improve mitochondrial dysfunction through SIRT1 signal pathways [15]. In a Parkinson's disease mouse model, the study showed that ARS protects neurons and stabilizes mitochondria [16]. In addition, ARS can reduce ROS from mouse tissues, lower the permeability of mitochondrial membranes and improve antioxidant activity. Thus, ARS slows down the aging process [17].

In order to comprehensively analyze the effect of Astragali radix on mitochondria, we used Astragali radix extracts to examine its effects on mouse kidney cells and mouse tissues respectively, revealing how Astragali radix modulates mitochondria in cells and organs in-vitro.

\section{Materials and Methods}

\subsection{Herbal Preparation}

Astragali radix herb was purchased at a Chinese medicine chain-store (Tongrentang, Beijing), and the herbal preparation involved chopping $50 \mathrm{~g}$ of the herb into small pieces. After soaking in $500 \mathrm{~mL}$ deionized water for an hour, the herb was extracted in boiling water for $30 \mathrm{~min}$. The procedure was repeated twice. The pooled extract was dried by evaporating the solvent under reduced pressure, and a water extract of Astragali radix was obtained with a yield of $14.4 \%(\mathrm{w} / \mathrm{w})$. 


\subsection{Cell Culture and Treatment}

M-1 mouse kidney collecting duct cell line was obtained from National Infrastructure of Cell Line Resource (Beijing, China, http://www.cellresource.cn). The cells were cultured as monolayers in DMEM/F12 medium (1:1) supplemented with $10 \%$ fetal bovine serum (FBS) and incubated in a humidified $5 \% \mathrm{CO}_{2}$ incubator at $37^{\circ} \mathrm{C}$. The medium was changed 2 - 3 times per week. Stock cells were grown in $10 \mathrm{~cm}$ culture dishes and split at a sub-cultivation ratio of 1:5.

To study the herbal effects on cells, M-1 cells were seeded at a density of 5 - 6 $\times 10^{5}$ cells/plate into $10 \mathrm{~cm}$ plates. After the cell attachment for $24 \mathrm{~h}$, the extract of Astragali radix (dissolved in phosphate-buffered saline; PBS) at $50 \mu \mathrm{g} / \mathrm{mL}$ was added to the medium of cells in the treatment group. Control cells (untreated) were given PBS only. After $4 \mathrm{~h}$, the culture medium was removed and fresh medium was added to the plates. The plates were then incubated for an additional $48 \mathrm{~h}$. At $24 \mathrm{~h}$ and $48 \mathrm{~h}$ respectively during the treatment, cells were collected using trypsin-EDTA $(0.25 \%)$ and centrifuged at $800 \mathrm{~g}$ for $5 \mathrm{~min}$. Then, the cells were re-suspended in $5 \mathrm{~mL}$ of PBS and subjected to the different assays. All experiments were performed in triplicate.

\subsection{Animal Care and Treatment}

Mice used in the experiments were purchased from Beijing Vital River Laboratory Animal Technology Co. Adult female C57BL/6J mice (8 months; $35 \pm 2$ g; specific pathogen-free) were maintained under a 12 -h dark/light cycle at about $22^{\circ} \mathrm{C}$, and allowed food and drinking water ad libitum in the Animal Care Facility. Animals were randomly divided into two groups with three animals in each group. In the treatment group, mice were intragastrically administered with $A s$ tragali radix extract (dissolved in distilled water; $0.1 \mathrm{~g} / \mathrm{mL}$ ) at a daily dose of 0.20 $\mathrm{mL} / 10 \mathrm{~g}$ for 7 days. Control animals received distilled water only. At $24 \mathrm{~h}$ after the last dosing, the animals were anaesthetized with isoflurane gas. The whole heart, liver, spleen, lung, kidney, brain and skeletal muscle (hind limb) tissues were excised and were stored in liquid nitrogen.

\subsection{Preparation of Tissue Homogenates}

Minced tissue samples were homogenized in ice cold PBS $(1 / 10, \mathrm{~g} / \mathrm{mL})$ with a Teflon-glass homogenizer. After that, the tissue extract was centrifuged at 3,000 $\mathrm{g}$ at $4^{\circ} \mathrm{C}$ for $5 \mathrm{~min}$ to remove cell debris and to obtain the final tissue homogenates which were subjected to measurement of ATP/ADP/AMP, SOD and GSH levels.

\subsection{Preparation of Mitochondrial Fractions}

Mitochondrial pellets were prepared from tissue homogenates $(200 \mu \mathrm{L})$ by centrifugation at $1,500 \mathrm{~g}$ at $4^{\circ} \mathrm{C}$ for $20 \mathrm{~min}$. Then the supernatants were centrifuged at $17,000 \mathrm{~g}$ at $4^{\circ} \mathrm{C}$ for $20 \mathrm{~min}$ to sediment the mitochondria. After that, the mitochondrial pellets were re-suspended in $400 \mu \mathrm{L}$ buffer (consisting of $210 \mathrm{mM}$ 
mannitol, $70 \mathrm{mM}$ sucrose, $10 \mathrm{mM} \mathrm{MgCl}_{2}, 5 \mathrm{mM} \mathrm{K}_{2} \mathrm{HPO}_{4}, 1 \mathrm{mM}$ EGTA and 10 $\mathrm{mM}$ Tris-base, $\mathrm{pH}$ 7.4) and reconstituted as mitochondrial fractions. The mitochondrial fractions were subjected to the measurement of ROS and MMP levels.

\subsection{Biochemical Analysis}

1) Measurement of Total Adenylate (TAP) Levels

To study adenosine triphosphate (ATP), adenosine diphosphate (ADP), and adenosine monophosphate (AMP) levels in tissue homogenates of $\mathrm{M}-1$ cells, a new HPLC analysis was employed [18]. A $1 \mathrm{~mL}$ aliquot of cell samples or tissue homogenates were centrifuged at $10,000 \mathrm{~g}$ for $5 \mathrm{~min}$ to collect the cells. Then 100 $\mu \mathrm{L}$ PBS and $40 \mu \mathrm{L}$ deionized water were added successively to rupture the cell membrane. After that, $360 \mu \mathrm{L}$ perchloric acid (6\%) was added to the samples on ice for an additional 10 minutes to remove the protein. After the cell extract was centrifuged at $10,000 \mathrm{~g}$ at $4^{\circ} \mathrm{C}$ for $5 \mathrm{~min} .300 \mu \mathrm{L}$ supernatant was neutralized with $40 \mu \mathrm{L}$ of $2 \mathrm{M} \mathrm{K}_{2} \mathrm{CO}_{3}$ and filtered through a $0.45 \mu \mathrm{m}$ filter. The neutralized cell extract $(10 \mu \mathrm{L})$ was used for determination of ATP, ADP, and AMP, which was carried out using HPLC with a mobile phase $\left(0.1 \mathrm{M} \mathrm{KH}_{2} \mathrm{PO}_{4}\right.$ buffer at $\mathrm{pH}$ $6.25)$ and $5 \%$ methanol (v/v) set at a rate of $0.6 \mathrm{~mL} / \mathrm{min}$ and a detection wavelength of $254 \mathrm{~nm}$. ATP, ADP and AMP levels were calculated by computing peak areas using injections of standard solutions of nucleotides with known concentrations. The total adenylate pool (TAP) was calculated by the following formulas: $[\mathrm{TAP}]=[\mathrm{ATP}]+[\mathrm{ADP}]+[\mathrm{AMP}]$. Finally, TAP levels in cells were normalized to the total cell protein.

2) Mitochondrial ROS Levels

To study the ROS levels in cells, $0.5 \mathrm{~mL}$ aliquots of cells were incubated with the DCFH-DA solution $(2 \mu \mathrm{M})$ at $37^{\circ} \mathrm{C}$ for $40 \mathrm{~min}$ in the dark. Then samples were washed two times with PBS for measurement. The fluorescence intensity was recorded at $485 \mathrm{~nm}$ (excitation) and $535 \mathrm{~nm}$ (emission) using a microplate reader (Tecan, Switzerland). ROS levels in cells were normalized to the total cell protein. ROS levels in tissue homogenates were determined by the method of Leung et al. [19]. In brief, $50 \mu \mathrm{L}$ aliquots of the mitochondrial fraction and $60 \mu \mathrm{L}$ DCFH-DA solution $(2 \mu \mathrm{M})$ were added into wells of a black micro-titer plate. The mixture was incubated at $37^{\circ} \mathrm{C}$ for 10 min under dark conditions. After the incubation, $50 \mu \mathrm{L}$ of incubation buffer ( $0.1 \mathrm{mM}$ EGTA, $5 \mathrm{mM} \mathrm{KH}_{2} \mathrm{PO}_{4}, 3 \mathrm{mM}$ $\mathrm{MgCl}_{2}, 145 \mathrm{mM} \mathrm{KCl}, 30 \mathrm{mM}$ Hepes, $\mathrm{pH} 7.4$ ) and $50 \mu \mathrm{L}$ of substrate solution (20 $\mathrm{mM}$ pyruvate and $10 \mathrm{mM}$ malate) were added. Fluorescence intensity (excitation of $485 \mathrm{~nm}$, emission of $535 \mathrm{~nm}$ ) of the reaction mixture was monitored every 5 min for $60 \mathrm{~min}$. Mitochondrial ROS levels were obtained from the fluorescence intensity of the sample after subtracting the value of a blank sample containing incubation buffer, substrate solution, and DCFH-DA.

3) Mitochondrial Membrane Potential Assay

Mitochondrial membrane potential (MMP) levels were quantified in accordance with the protocol of the Mitochondrial membrane potential assay kit 
(Product No.: C2006; Beyotime, China). To study the MMP levels in cells, 500 $\mu \mathrm{L}$ aliquots of cells were incubated with a JC-1 probe at $37^{\circ} \mathrm{C}$ for $20 \mathrm{~min}$ in the dark. After the incubation, cells were washed twice with ice-cold JC-1 buffer solution. The JC-1 probe enters the mitochondrial matrix where it accumulates and appears as bright red. But, the JC- 1 cannot accumulate within the mitochondria and remains in the cytoplasm as a monomeric form with green fluorescence. The aggregate JC-1 (red) emits at $590 \mathrm{~nm}$ after excitation at $525 \mathrm{~nm}$. The monomeric JC-1 (green) emits at $530 \mathrm{~nm}$ after excitation at $490 \mathrm{~nm}$. The fluorescence intensity was recorded using a microplate reader (Tecan, Switzerland). The value of MMP was calculated by the ratio of red to green. To study the MMP levels in tissue homogenates, $50 \mu \mathrm{L}$ aliquots of the mitochondrial fractions were used according the same method.

4) Protein Assay

The amount of cells used for the different experimental groups was evaluated using the protein assay. Protein concentrations were determined using a protein assay kit (Product No.: P0006C; Beyotime, China) containing bovine serum albumin as the standard $(0-1.5 \mathrm{mg} / \mathrm{mL})$. An aliquot of $0.5 \mathrm{~mL}$ cell samples was centrifuged at $3000 \mathrm{~g}$ for $5 \mathrm{~min}$ to collect the cells. Then the cells were incubated with Triton (0.1\%) for $30 \mathrm{~min}$. After cell disruption, samples were centrifuged at $11,000 \mathrm{~g}$ for $5 \mathrm{~min}$ to remove cell residues. Finally, the optical density was measured at a wavelength of $595 \mathrm{~nm}$ using a microplate reader (Tecan, Switzerland).

5) Cell Viability Assay

In brief, an aliquot of $0.5 \mathrm{~mL}$ cell samples was centrifuged at 3,000 $\mathrm{g}$ for $5 \mathrm{~min}$ to collect the cells. Then the cells were re-suspended in $100 \mu \mathrm{L}$ culture medium and seeded in 96-well plates. Finally, $10 \mu \mathrm{L}$ CCK- 8 was added to the wells and the plates were incubated for an additional $3 \mathrm{~h}$. The optical density (OD) was measured at a wavelength of $450 \mathrm{~nm}$ by using a using a microplate reader (Tecan, Switzerland).

6) Antioxidant Capacity Assay

Antioxidant capacity in M-1 cells and the different tissue homogenates was evaluated by SOD enzyme activity and the content of GSH. The SOD assay kit with WST-8 (Product No. S0101; Beyotime, China) and the Glutathione assay kit (Product No.: S0052; Beyotime, China) were used for the evaluation of SOD and GSH levels, respectively, according to the manufacturer's instructions. The absorbance was assessed at $450 \mathrm{~nm}$ and $412 \mathrm{~nm}$ respectively using a microplate reader. SOD and GSH levels in cell homogenates were normalized to the total cell protein.

\subsection{Statistical Analysis}

Values of the different measurement were normalized to the respective mean control value from untreated samples and expressed as percent control. To statistically evaluate the cell's responses to A.R., the results of treatments at $24 \mathrm{~h}$ and $48 \mathrm{~h}$ were combined as a whole (just divided into treated and control groups) for the analysis. All data are expressed as mean \pm standard deviation 
(SEM). Data were analyzed by two-way analysis of variance (ANOVA) followed by Fisher's LSD multiple comparisons tests. Comparisons between the two groups were done by Student's t-test. Analysis was achieved by using InStat software (from GraphPad) where $\mathrm{p}<0.05$ was considered to be statistically significant.

\section{Results}

\subsection{The Effect of Astragali radix on Mitochondria in M-1 Cells}

Figure 1 shows the effect of Astragali radix on mitochondrial functions in M-1 cells including TAP generation, ROS production and MMP activity. The treatment with Astragali radix significantly increased cellular TAP and MMP (Figure 1(a) and Figure 1(c)), whereas the total ROS was significant decreased (Figure 1(b)). The effects of Astragali radix on the antioxidant capacity are shown in Figure 2. The change of SOD activity in treated cells was not significant (Figure 2(a)), although Astragali radix could cause a significant increase in GSH in M-1 cells (Figure 2(b)). The changes in cell growth and cell viability were not significant after Astragali radix treatment (Figure 3(a) and Figure 3(b)).

(a)

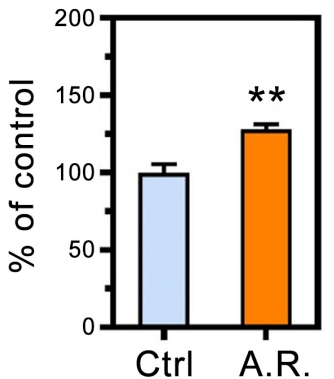

(b)

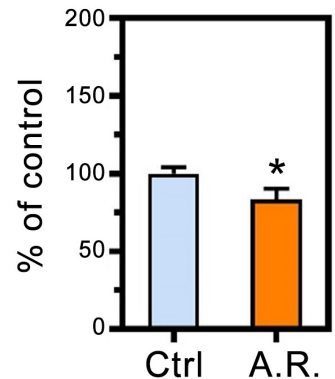

(c)

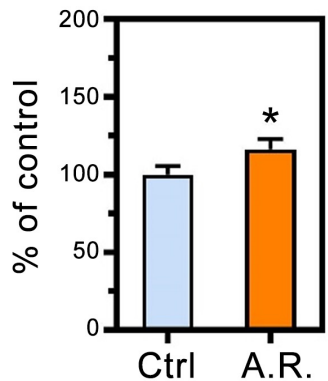

Figure 1. Effect of Astragali radix (A.R.) extracts on mitochondrial related markers in M-1 cells. (a) TAP; (b) ROS; (c) MMP. Data expressed as percent control with respect to the untreated control. * $\mathrm{P}<0.05 ;{ }^{*} \mathrm{P}<0.01$.

(a)

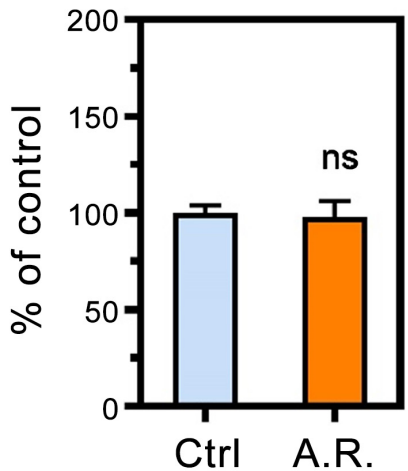

(b)

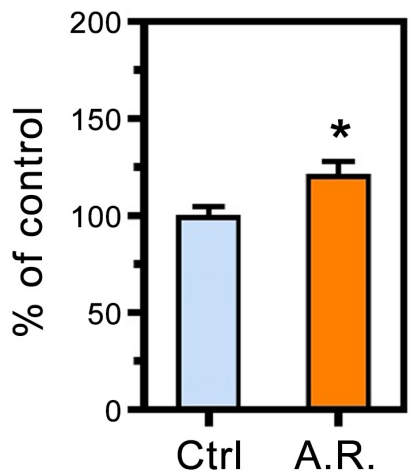

Figure 2. Effect of Astragali radix (A.R.) extracts on antioxidant capability related markers in M-1 cells. (a) SOD; (b) GSH. Data expressed as percent control with respect to the untreated control. ${ }^{\star} \mathrm{P}<0.05 ;{ }^{*} \mathrm{P}<0.01$. 
(a)

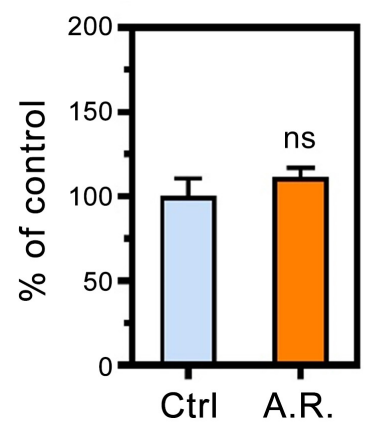

(b)

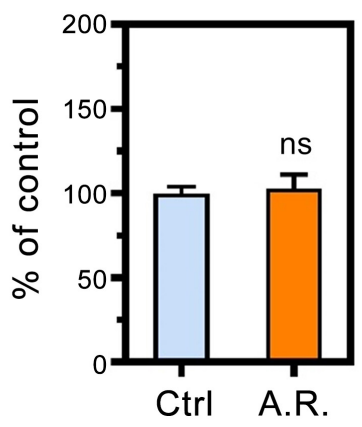

Figure 3. Effect of Astragali radix (A.R.) extracts on cell numbers (a) and cellular viability (b) in M-1 cells. Data expressed as percent control with respect to the untreated control. ${ }^{*} \mathrm{P}<0.05 ;{ }^{* *} \mathrm{P}<0.01$.

\subsection{The Effect of Astragali radix on Mitochondria in Mouse Tissues}

Astragali radix caused a significant decrease in mitochondrial content of TAP in most of the mouse tissues examined (including: heart, liver, spleen, kidney and muscle), with only the lung and brain showing no significant changes (Figure 4(a)). In the case of ROS levels, Astragali radix significantly decreased ROS in most of the mouse tissues (heart, spleen, lungs, kidney and muscle), but paradoxically showed a significant increase in liver tissue and with no change in brain tissue (Figure 4(b)). As shown in Figure 4(c), Astragali radix significantly increased MMP in the heart, liver and lung tissue, but there was no statistical difference in other organs (spleen, kidney, brain, muscle).

As for antioxidant capability, SOD activity in heart and muscle was elevated significantly, but in other tissues SOD activity did not change significantly (Figure 5(a)). While Astragali radix showed a large effect on GSH in nearly all mouse tissues, as shown in Figure 5(b), with GSH in heart, spleen and lung tissues being increased significantly, whereas GSH in liver, kidney and brain tissue decreased significantly-and only the GSH in the muscle did not change.

Figure 6 shows the Astragali radix treatment did not produce any significant changes in the weight of organs in any tissue.

\section{Discussion}

According to the contemporary life science research, mitochondria are the center for energy metabolism and play the most important role in the life activities. The mitochondrial electron transport chain (ETC) is vital for cellular energy production, and this process is associated with the production of ROS. The changes in the adenylate content directly reflect the real conditions of cellular energy supply and the state of cellular activities. Mitochondria provide adenylate to participate in almost all of the oxidation and reduction reactions in the organism, which represent regulatory and defensive functions.

According to Traditional Chinese Medicine theory, Qi is one of the most im- 
portant basic concepts because it governs all activities of life and regulates the balance between "yin" and "yang". In Traditional Chinese Medicine there are herbal remedies which are believed to increase Qi in the body. These are called Qi-invigorating herbs. According to the ancient medical text "Shen Nong Ben Cao Jing", Astragali radix has the effects of invigorating Qi, elevating Yang and alleviating depression, and is commonly used as "Qi-invigoration" herb in clinical practice [20]. Qi-invigorating herbs can be viewed in terms of an up-regulated.

(a)

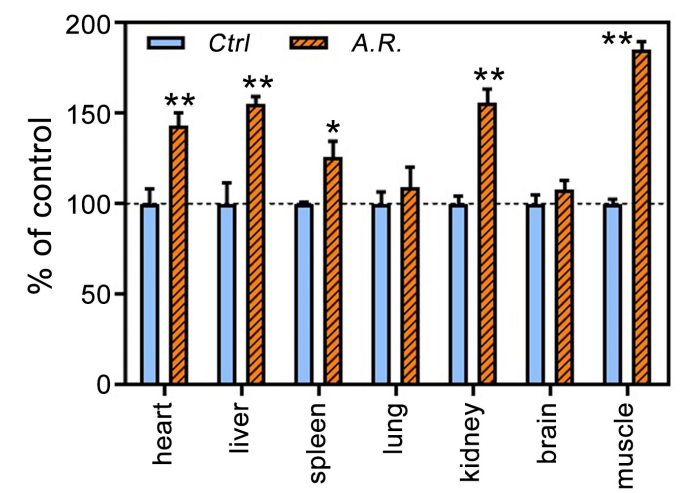

(b)

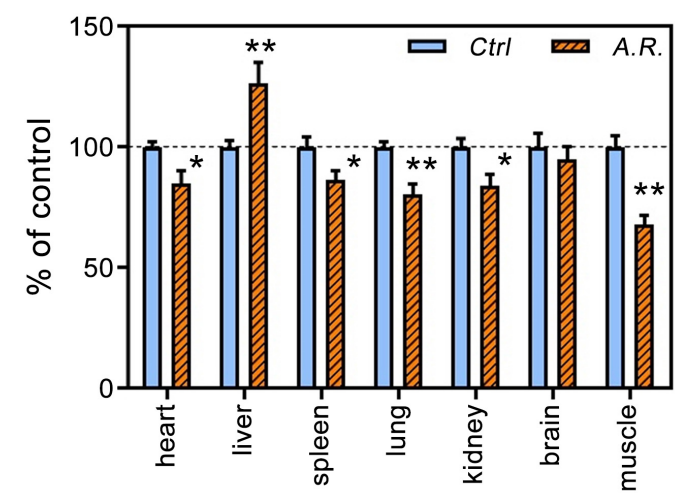

(c)

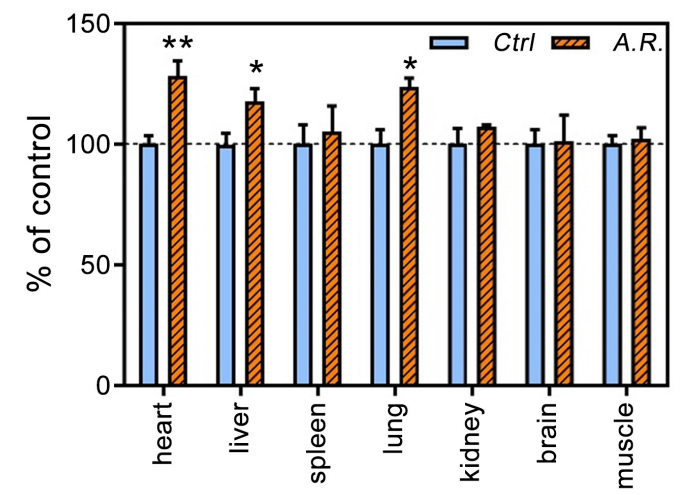

Figure 4. Effect of Astragali radix (A.R.) extracts on mitochondrial related markers in various tissues of mice. (a) TAP; (b) ROS; (c) MMP. Data expressed as percent control with respect to the untreated control. ${ }^{\star} \mathrm{P}<0.05$; ${ }^{\star *} \mathrm{P}<0.01$. 
(a)

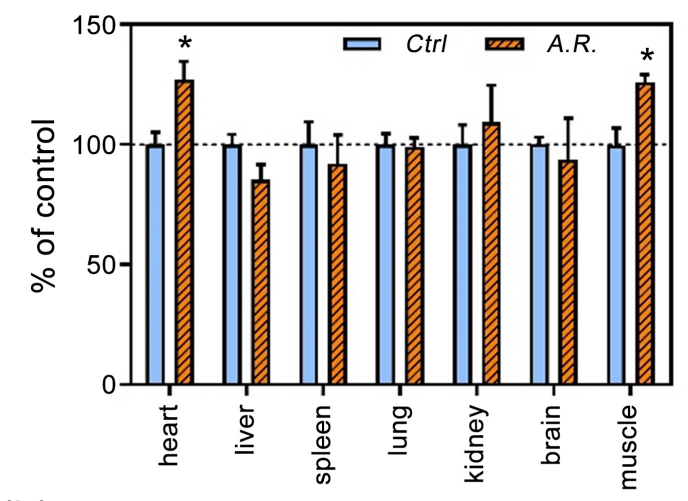

(b)

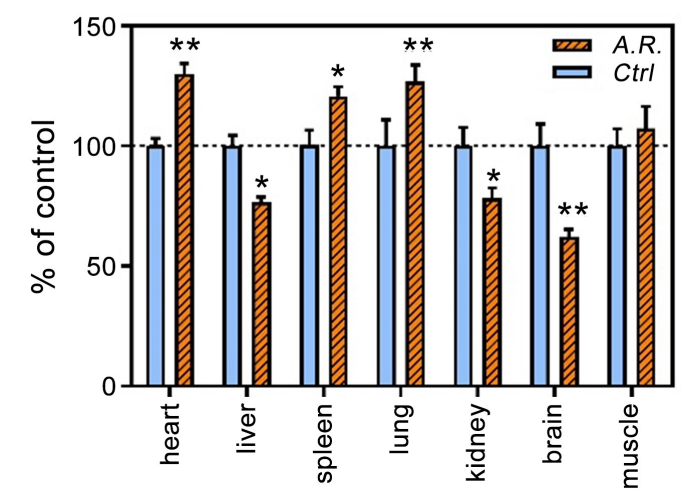

Figure 5. Effect of Astragali radix (A.R.) extracts on antioxidant capability related markers in various tissues of mice. (a) SOD; (b) GSH. Data expressed as percent control with respect to the untreated control. ${ }^{*} \mathrm{P}<0.05 ;{ }^{* *} \mathrm{P}<0.01$.

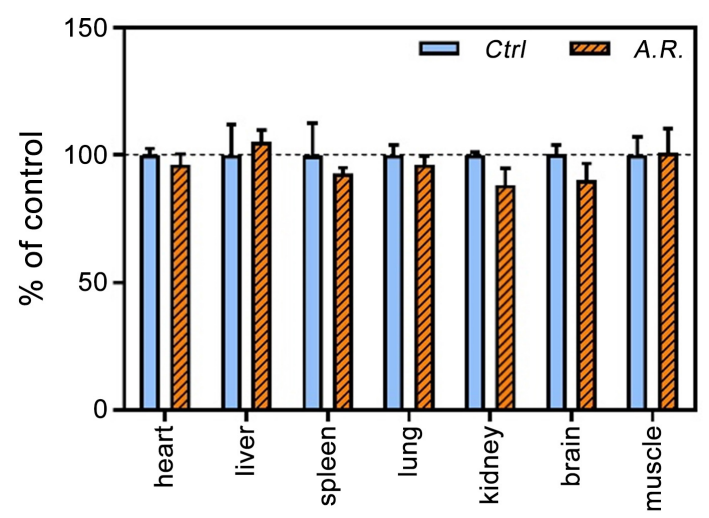

Figure 6. Effect of Astragali radix (A.R.) extracts on the weight in various tissues of mice. Data expressed as percent control with respect to the untreated control. ${ }^{*} \mathrm{P}<0.05 ;{ }^{* *} \mathrm{P}<0.01$.

energy status, as well as the stimulation of growth and development in the human body. Therefore, the investigation of the biological activities and the underlying mechanisms in the "Qi-invigoration" process is of great interest. In this regard, an early study had preliminarily found a relationship between "Qi-invi- 
gorating" actions and changes in ATP levels in cultured rat myocytes as well as in rat skeletal muscle [21]. Consist with this, a previous study using both in-vitro and in-vivo studies with animals, has shown that Panax Ginseng, a famous "Qi-invigoration" herb, is capable of enhancing mitochondrial energy production in both the H9c2 cardiomyocytes and rat hearts [22]. Furthermore, a recent experimental study showed that "Qi-invigoration" by Panax Ginseng stimulated the proliferation of cultured rat splenocytes and increased mitochondrial energy levels in rat intestine [23].

These studies inspired us to further explore the mechanisms of "Qi-invigoration" using both cell-based and animal-based assay systems. In the present study, M-1 renal cells of mouse kidneys were used. In TCM, "kidney" is regarded as the basis of "Qi" and the "kidney" plays a most important role in regulating human body functions and providing "vital energy". In the present study the biochemical mechanisms of action of Astragali radix was investigated. In the present study using M-1 cells, "Qi-invigoration" using Astragali radix was found to stimulate the levels of mitochondrial TAP and enhance the levels of MMP, while the levels of ROS in the cells decreased significantly. And although SOD activity showed no significant changes, the levels of GSH increased significantly indicating an enhanced antioxidant capacity.

This result reveals a basic mechanism of Astragali radix as a pathway for upregulating cellular energy (ATP) levels and for enhancing GSH to counteract oxidative stress. However, GSH levels in mice kidney decreased dramatically and SOD activity increased slightly (not significant). These results support the hypothesis that Qi-invigoration activates the mitochondria and that there is a correlation between Qi and energy metabolism in mitochondria.

It seems likely that the "Qi-invigorating" property of Astragali radix doesn't enhance antioxidant capacity in mouse's kidney. This result is not surprising as Astragali radix extract had direct access to M-1 cells in-vitro, whereas in-vivo the herb first goes through the digestion system and then acts selectively on different organs. This target specificity cannot be explained by contemporary western medical science. Organ specificity, however, can be explained by the meridian tropism theory in Traditional Chinese Medicine. This theory predicts that $A s$ tragali radix acts preferably on the meridian of the "Spleen" and the "Lung".

Based on the "meridian tropism" theory, Astragali radix can preferentially invigorate Qi in the "Spleen" and "Lung". Organ-specific biological actions produced by Astragali radix treatment were observed in the present study. For example, the effect of Astragali radix on the "spleen" and "lung" showed similar trends in their biological effects, i.e. the enhancement of mitochondrial TAP, a dramatically decrease in ROS and an enhancement of GSH. The results offer a potential insight for understanding "meridian tropism" in Astragali radix. Based on the results, we can conclude that Qi-invigorating herbs are able to boost the energy production of visceral organs in general, but for the meridian organs the herb belongs to, Qi-invigoration means simultaneous increases in both energy 
production and antioxidant capacity.

Astragali radix was found to stimulate mitochondrial TAP production either significantly or slightly in all the organs used in this study. Reduced ROS was found in almost all the organs except for the "liver". As for the antioxidant capacity of Astragali radix, the effects varied in different organs. Comparing the effects of Astragali radix on the various visceral organs, we conclude that the data from the present study suggests a correlation between the herb's "Qi-invigorating" activity and mitochondrial energy metabolism in the body. Such a correlation is consistent with the theory of "Qi" in Traditional Chinese Medicine.

In conclusion, the results obtained from the present study indicate that a Qi-enhancing herb up-regulates mitochondrial energy production. This supports the hypothesis that Qi is a type of "subtle energy" which resonates with the chemical energy from ATP in our bodies. Furthermore, the Astragali radix "Qi-invigoration" may produce beneficial effects in the body in a holistic and holographic manner. Thus, if Qi is holographic or quantum holographic in nature [24], all the individual mitochondria in the human body would be energetically connected and act as a coordinated whole system. Therefore, enhancement of mitochondrial adenylate would be present in all organs and in all tissues throughout the body simultaneously. However, for the meridian organs Astragali radix belongs to, it has a synergistic effect on the enhancement of energy metabolism and antioxidant capability, and consequently, a reduction in ROS. This result provides insights in understanding the biochemical basis of "meridian tropism" for Qi-invigorating herbs like Astragali radix.

\section{Acknowledgements}

The authors would like to thank the ENN Research Fund.

\section{Conflicts of Interest}

The authors declare no conflicts of interest regarding the publication of this paper.

\section{References}

[1] Zhang, W.M., Ma, W.R., Zhang, J., Song, X.P., Sun, W.J. and Fan, Y.P. (2017) The Immunoregulatory Activities of Astragalus Polysaccharide Liposome on Macrophages and Dendritic Cells. International Journal of Biological Macromolecules, 105, 852-861. https://doi.org/10.1016/j.ijbiomac.2017.07.108

[2] Chen, R.F., Shao, H., Lin, S.Q., Zhang, J.J. and Xu, K.Q. (2011) Treatment with Astragalus membranaceus Produces Antioxidative Effects and Attenuates Intestinal Mucosa Injury Induced by Intestinal Ischemia-Reperfusion in Rats. The American Journal of Chinese Medicine, 39, 879-887. https://doi.org/10.1142/s0192415x11009275

[3] Zhang, P.J., Wang, J., Wang, W.X., Liu, X.H., Liu, H.Y., Li, X.T. and Wu, X.H. (2017) Astragalus Polysaccharides Enhance the Immune Response to Avian Infectious Bronchitis Virus Vaccination in Chickens. Microbial pathogenesis, 111, 81-85. https://doi.org/10.1016/j.micpath.2017.08.023 
[4] Zhang, J., Gu, J.Y., Chen, Z.S., Xing, K.C. and Sun, B. (2015) Astragalus Polysaccharide Suppresses Palmitate-Induced Apoptosis in Human Cardiac Myocytes: The Role of Nrf1 and Antioxidant Response. International Journal of Clinical and Experimental Pathology, 8, 2515-2524. https://www.ncbi.nlm.nih.gov/pmc/articles/PMC4440066/

[5] Shao, B.M., Xu, W., Dai, H., Tu, P.F., Li, Z.J. and Gao, X.M. (2004) A study on the Immune Receptors for Polysaccharides from the Roots of Astragalus membranaceus, a Chinese Medicinal Herb. Biochemical and Biophysical Research Communications, 320, 1103-1111. https://doi.org/10.1016/j.bbrc.2004.06.065

[6] Zhou, Q.L., Meng, G.W., Teng, F., Sun, Q. and Zhang, Y.S. (2018) Effects of Astragalus Polysaccharide on Apoptosis of Myocardial Microvascular Endothelial Cells in Rats Undergoing Hypoxia/Reoxygenation by Mediation of the PI3K/Akt/eNOS Signaling Pathway. Journal of Cellular Biochemistry, 119, 806-816. https://doi.org/10.1002/jcb.26243

[7] Shahzad, M., Shabbir, A., Wojcikowski, K., Wohlmuth, H. and Gobe, C.G. (2016) The Antioxidant Effects of Radix Astragali (Astragalus membranaceus and Related Species) in Protecting Tissues from Injury and Disease. Current Drug Targets, 17, 1331-1340. https://doi.org/10.2174/1389450116666150907104742

[8] Liu, Y.B., Fiskum, G. and Schubert, D. (2002) Generation of Reactive Oxygen Species by the Mitochondrial Electron Transport CHAIN. Journal of Neurochemistry, 80, 780-787. https://doi.org/10.1046/j.0022-3042.2002.00744.x

[9] Li, X.X., Qu, L., Dong, Y.Z., Han, L.F., Liu, E.W., Fang, S.M., Zhang, Y. and Wang, T. (2014) A Review of Recent Research Progress on the Astragalus Genus. Molecules, 19, 18850-18880. https://doi.org/10.3390/molecules191118850

[10] Murphy, M.P. (2009) How Mitochondria Produce Reactive Oxygen Species. Biochemical Journal, 417, 1-13. https://doi.org/10.1042/BJ20081386

[11] Hegde, M.L., Mantha, A.K., Hazra, T.K., Bhakat, K.K., Mitra, S. and Szczesny, B. (2012) Oxidative Genome Damage and Its Repair: Implications in Aging and Neurodegenerative Diseases. Mechanisms of Ageing and Development, 133, 157-168. https://doi.org/10.1016/j.mad.2012.01.005

[12] Ryan, B.J., Hoek, S., Fon, E.A. and Wade-Martins, R. (2015) Mitochondrial Dysfunction and Mitophagy in Parkinson's: From Familial to Sporadic Disease. Trends in Biochemical Sciences, 40, 200-210. https://doi.org/10.1016/j.tibs.2015.02.003

[13] Chakrabarty, S., Kabekkodu, S.P., Singh, R.P., Thangaraj, K., Singh, K.K. and Satyamoorthy, K. (2018) Mitochondria in Health and Disease. Mitochondrion, 43, 25-29. https://doi.org/10.1016/j.mito.2018.06.006

[14] Yang, F., Yan, G., Li, Y., Han, Z., Zhang, L., Chen, S., Feng, C., Huang, Q., Ding, F. and Yu, Y. (2016) Astragalus Polysaccharide Attenuated Iron Overload-Induced Dysfunction of Mesenchymal Stem Cells Via Suppressing Mitochondrial ROS. Cellular Physiology and Biochemistry, 39, 1369-1379. https://doi.org/10.1159/000447841

[15] Huang, Y.F., Lu, L., Zhu, D.J., Wang, M., Yin, Y., Chen, D.X. and Wei, L.B. (2016) Effects of Astragalus Polysaccharides on Dysfunction of Mitochondrial Dynamics Induced by Oxidative Stress. Oxidative Medicine and Cellular Longevity, 2016, Article ID: 9573291. http://dx.doi.org/10.1155/2016/9573291

[16] Liu, H., Chen, S., Guo, C., Tang, W., Liu, W. and Liu, Y. (2018) Astragalus Polysaccharide Protects Neurons and Stabilizes Mitochondrial in a Mouse Model of Parkinson Disease. Medical Science Monitor. International Medical Journal of Experimental and Clinical Research, 24, 5192-5199. https://doi.org/10.12659/MSM.908021 
[17] Li, X.-T., Zhang, Y.-K., Kuang, H.-X., Jin, F.-X., Liu, D.-W., Gao, M.-B., Liu, Z. and Xin, X.-J. (2012) Mitochondrial Protection and Anti-Aging Activity of Astragalus Polysaccharides and Their Potential Mechanism. International Journal of Molecular Sciences, 13, 1747-1761. https://doi.org/10.3390/ijms13021747

[18] Chen, Y.J., Wu, X.X. and Li, T.J. (2018) A Method for Detecting the Energy of Organism. Patent No. 11422682.

[19] Leung, H.Y., Chiu, P.Y., Poon, M.K. and Ko, K.M. (2005) A Yang-Invigorating Chinese Herbal Formula Enhances Mitochondrial Functional Ability and Antioxidant Capacity in Various Tissues of Male and Female Rats. Rejuvenation Research, 8, 238-247. https://doi.org/10.1089/rej.2005.8.238

[20] Gao, X.M. (2007) Chinese Material Medicine. China Press of Traditional Chinese Medicine, Beijing.

[21] Li, X.T., Zhang, J.J. and Chen, W.W. (2000) The Effects of TCM Qi-Invigorating, Qi Regulating Drugs and Polysaccharides on the Energy Charge of Rat Skeletal Muscle Cells. Journal of Beijing University of Traditional Chinese Medicine, 23, 36-38. https://en.cnki.com.cn/Article_en/CJFDTotal-JZYB200005011.htm

[22] Wong, H.S., Cheung, W.F., Tang, W.L. and Ko, K.M. (2012) “Qi-Invigorating” Chinese Tonic Herbs (Shens) Stimulate Mitochondrial ATP Generation Capacity in H9c2 Cardiomyocytes in Situ and Rat Hearts ex Vivo. Chinese Medicine, 3, 101-105. https://doi.org/10.4236/cm.2012.32016

[23] Leong, P.K., Leung, H.Y., Chan, W.M. and Ko, K.M. (2019) Pharmacological Investigation of "Meridian Tropism" in Three "Shen" Chinese Herbs. Chinese Medicine, 10, 121-135. https://doi.org/10.4236/cm.2019.104007

[24] Mitchel, E.D. and Staretz, R. (2011) The Quantum Hologram And the Nature of Consciousness. Journal of Cosmology, 14, 1-9.

http://journalofcosmology.com/Consciousness149.html 